\title{
Green Trade Barriers with Our Country Agricultural Product Export Trade
}

\section{Liu Tao}

School of Economics, Shanghai University, Shanghai, China

\section{Email address:}

18817638824@163.com

\section{To cite this article:}

Liu Tao. Green Trade Barriers with Our Country Agricultural Product Export Trade. Science Innovation. Vol. 4, No. 3, 2016 , pp. 168-171. doi: 10.11648/j.si.20160403.19

Received: June 26, 2016; Accepted: July 19, 2016; Published: July 25, 2016

\begin{abstract}
After entering WTO, Chinese agriculture develop in the high speed. Now our country is not only an big agricultural country, but also an agricultural exporter. However, in recent years, so as to go out of the predicament, safeguard national interests, the developed countries set up green trade barriers which is a new form of non-tariff barriers and rely on its advanced science and technology, abundant capital, leading environmental standards. With the rising of green trade barriers, the trade friction of our country increase and agricultural product export quantity slump. The agricultural trade situation of our country is not optimistic. Based on our country agricultural product encounters the causes and effects of the green barriers, we proposed to our country agricultural exports respond to green trade barrier of feasible countermeasures and suggestions.
\end{abstract}

Keywords: Green Trade Barriers, Agricultural Product, Export, International Economy

\section{绿色贸易壁垒与我国农产品出口贸易}

\section{刘涛}

经济学院, 上海大学, 上海, 中国

\section{邮箱}

18817638824@163.com

\begin{abstract}
摘要：加入WTO以来, 中国农业迎来了高速发展, 现在我国不仅是农业大国, 而且还是农业出口大国。但是, 近些年来, 发达国家为了走出经济困境，维护国家利益，不惜依靠其先进的科技、雄厚的资金、领先的环保标准，设置了一种新 形式的非关税壁垒即绿色贸易壁垒。绿色贸易壁垒的日益抬头, 使我国的贸易磨擦不断增加, 农产品出口数量大幅度 下滑, 我国农业贸易形势不容乐观。本文结合我国农产品遭遇绿色壁垒的原因和影响, 具体问题具体分析, 多角度提 出对我国农业出口切实可行的应对绿色贸易壁垒的对策和建议。
\end{abstract}

关键词: 绿色贸易壁垒, 农产品, 出口, 国际经济

\section{1. 绿色贸易壁垒相关概述}

\section{1. 绿色贸易壁垒的概念}

所谓绿色贸易壁垒 (Green Barriers, 简称GBS), 也称为 环境贸易壁垒 (Environmental Trade Barriers, 简称ETBS)，
起初是为了保护自然环境、生态安全、人类健康。但发展到 后期，一些发达国家以保护自然资源、生态环境和人类健康 为名, 保护本国市场为目的, 通过一系列复杂苛刻的环保制 度和标准等手段, 对来自他国和地区的产品和服务设置层层 障碍, 限制外国产品进入本国市场的方式而形成的新型非关 税贸易壁垒。 


\section{2. 绿色贸易壁垒的表现形式}

随着国际贸易的快速发展，绿色贸易壁垒被各国广泛使 用，使其表现形式多种多样，最常见的主要有:

\subsection{1. 绿色关税制度}

发展中国家由于经济发展水平有限、科学技术水平不是 很高, 生产出来的一些产品可能会对生态环境造成一定的影 响, 发达国家利用这一机会, 经常对发展中国家这些产品征 收进口附加税, 或者限制和禁止产品进口。然而, 这样的标 准并非内外一致, 歧视性色彩非常强烈, 实际上就是为了阻 止或者减少国外产品进口、保护本土产品。

\subsection{2. 绿色补贴制度}

治理环境和保护资源的费用是巨大的, 这部分费用也应 该包括在产品成本里, 这样的话企业需要承担的费用巨大。 发展中国家的很多企业很难负担的起如此高昂的费用, 因此, 政府不得不对企业保护环境所支付的费用给予一定的补贴。 发达国家以此为借口, 对发展中国家出口来的产品征收巨额 的反补贴税，以达到保护本国产业的目的。

\subsection{3. 绿色标准制度}

绿色标准制度主要包含: 绿色技术标准、绿色环境标志、 绿色包装制度、绿色卫生检疫制度。发达国家的经济水平、 科技水平非常高, 各个行业都处于绝对领先的地位。因此, 其技术标准、环境标准、包装标准、卫生标准都要很高, 这 些标准非常严格, 有些近乎苛刻, 发展中国家很难达到这些 标准, 导致发展中国家的很多产品都很难进入发达国家市场。

\section{2. 我国农产品出口的现状}

\section{1. 我国农产品出口的主要市场和主要产品}

发达国家市场仍然是我国农产品出口的主要市场, 虽 然2015年我国对发达国家的农产品出口普遍下降，但依旧
占我国农产品出口总额的 $60 \%$, 是我国农产品出口的主战 场。东盟、中东等新兴市场近年来出口保持持续增长, 是 我国农产品出口的重要市场。下面列举2015年我国农产品 出口的几个主要市场: 对东盟农产品出口额为 147.5 亿美 元, 较去年增长 $9 \%$, 目前仍然是我国最大的农产品出口市 场; 日本是我国第二大农产品出口市场, 对日农产品出口 总额为 102 亿美元, 由于近几年来日本经济低迷, 我国对 日农产品出口已经连续三年下降, 这一年下降幅度更是高 达 $8.3 \%$; 欧盟是我国农产品出口的传统市场, 虽然近些年 来出口额有所下滑, 但依旧是我国农产品出口的第三大市 场, 进口我国农产品 81.5 亿美元，同比下降 $3.7 \%$; 第四大 市场是美国, 对美国的农产品出口额是 73.5 亿美元, 较去 年下降 $1 \%$; 澳大利亚也是我国重要的农产品出口市场, 对 澳大利亚出口农产品 9.7 亿美元, 下降 $4.9 \%$; 近些年中东 市场表现的很稳定, 这一年我国农产品对中东的出口增长 达到 $5.6 \%$, 出口金额为 28.3 亿美元。

水产品、蔬菜、水果和肉类产品是我国出口的主要产 品。2015年, 我国水产品出口额为 200.2 亿美元, 蔬菜出 口额为 90.2 亿美元, 水果出口额为 45.8 亿美元, 肉类产品 出口额为 28 亿美元, 这四类产品的出口额占我国农产品出 口总额的 $51.9 \%$ 。其中水产品、肉类产品的出口额同比去 年略有下降, 主要是由于全球经济低迷、需求不足, 而水 产品、肉类产品的需求弹性又比较大, 所以导致其出口额 的下降; 与水产品、肉类产品不同, 蔬菜、水果的出口今 年依然保持增长, 这主要是由其刚需型的产品性质决定的。

\section{2. 农产品出口总额占进出口总额不断降低}

进入 21 世纪以来, 我国的国际地位不断提高, 对外贸 易发展迅猛, 使我国很快发展成为贸易大国, 其中农产品 进出口贸易额迅速增加, 中国农产品贸易在世界农产品贸 易中的地位举足轻重。

表1 我国农产品进出口贸易额（单位：亿美元）。

\begin{tabular}{|c|c|c|c|c|c|c|c|}
\hline \multirow{2}{*}{ 年度 } & \multirow{2}{*}{ 进出口 } & \multirow{2}{*}{ 出口 } & \multirow{2}{*}{ 进口 } & \multirow{2}{*}{ 出口总额/进出口总额 } & \multicolumn{3}{|c|}{ 比上年增减 } \\
\hline & & & & & 进出口 & 出口 & 进口 \\
\hline 2005 & 558.3 & 271.8 & 286.5 & 48. $7 \%$ & 9. $3 \%$ & $17.7 \%$ & 2. $4 \%$ \\
\hline 2006 & 630.2 & 310.3 & 319.9 & $49.2 \%$ & $12.9 \%$ & $14.1 \%$ & $11.7 \%$ \\
\hline 2007 & 775.9 & 366.2 & 409. 7 & $47.2 \%$ & $23.1 \%$ & 18. $0 \%$ & $28.1 \%$ \\
\hline 2008 & 985.5 & 402.2 & 583.3 & $40.8 \%$ & $27.0 \%$ & $9.8 \%$ & $42.4 \%$ \\
\hline 2009 & 913.8 & 392.1 & 521.7 & $42.9 \%$ & $-7.3 \%$ & $-2.5 \%$ & $-10.6 \%$ \\
\hline 2010 & 1208.0 & 488.8 & 719.2 & $40.5 \%$ & $32.2 \%$ & $24.7 \%$ & $37.8 \%$ \\
\hline 2011 & 1540.3 & 601.3 & 939.1 & $39.0 \%$ & $27.5 \%$ & 23. $0 \%$ & $30.6 \%$ \\
\hline 2012 & 1739.5 & 625. 0 & 1114.4 & $35.9 \%$ & $13.0 \%$ & $4.0 \%$ & $18.7 \%$ \\
\hline 2013 & 1850.0 & 671.0 & 1179.1 & $36.3 \%$ & $6.3 \%$ & $7.2 \%$ & $5.8 \%$ \\
\hline 2014 & 1928. 2 & 713.4 & 1214.8 & $37.0 \%$ & $4.2 \%$ & $6.3 \%$ & 3. $0 \%$ \\
\hline 2015 & 1861.0 & 701.8 & 1159.2 & $37.7 \%$ & $-3.5 \%$ & $-1.6 \%$ & $-4.6 \%$ \\
\hline
\end{tabular}

注: 以上统计数据由商务部网站统计整理得来。 
根据商务部报告整理结果，从表1可得，我国农产品 的进出口总额不断增加, 其中 2005 年农产品的进出口总额 是558. 3亿美元, 到2015年增加至 1861.0 亿美元, 增加了 1302. 4亿美元。另外，除了受2008年金融危机和2015年世 界经济低迷的影响, 农产品进出口总额有所下降, 其余年 份都保持增长状态, 并且其增长速度很快, 其中2010年竟 增长达到 $32.2 \%$, 增长速度惊人。

当然, 进出口总额的快速增长必然伴随着出口总额和 进口总额的增长, 从表 1 可以看出, 2005年农产品进、出 口总额分别为 286.5 亿美元和 271.8 亿美元, 贸易顺差为 -14.7 亿美元, 出口总额占进出口总额的 $48.7 \%$, 到 2015 年, 农产品进、出口总额分别为 1159.2 亿美元和 701.8 亿 美元, 贸易顺差为 -457.4 亿美元, 出口总额占进出口总额 的 $37.7 \%$, 可见我国农产品出口总额占进出口总额大幅度 降低。其主要原因在于我国农产品进口增长速度远远高于 农产品出口增长速度, 以2005年为基数, 2015年农产品出 口总额比 2005 年增长了 $258.2 \%$, 而进口总额却比 2005 年增 长了 $404.6 \%$ 。

\section{3. 农产品出口频繁遭遇绿色贸易壁垒}

日本是我国农产品出口的主要市场, 但是日本对我国 农产品的检验标准也相当严格。2006年5月，日本正式施 行《食品中残留农业化学品肯定列表制度最终草案》, 简 称《肯定列表制度》, 该制度规定的标准极为苛刻, 其对 每种农产品设计的残留限量标准平均为 200 项, 因此日本 的肯定列表制度被公认为是最严格的检测标准。该制度的 实施, 对我国农产品出口产生了极大的影响, 甜踠豆、鳗 鱼、活泥鲀等陆续被查出药物残留超标。当年6月, 我国 农产品出口额同比下降18\%, 水产品的对日出口基本停止。 欧盟是我国木制品出口的第二大市场，其 $70 \%$ 的木制品都 是从中国进口, 而欧盟一直认为我国是非法采伐比较严重 的国家。因此, 2013年欧盟出台了木材法规, 这一法规具 有一定的针对性，抬高了我国木制品的门槛，对我国木制 品出口的冲击非常大。

\section{3. 我国农产品出口遭遇绿色贸易壁垒的原因}

我国农产品出口遭遇绿色贸易壁垒有内部原因和外 部原因, 外部原因主要是发达国家对本国农业的保护和支 持、国际社会越来越重视生态环境和食品安全、发达国家 具有较高的技术标准和检测水平等。这些外部原因带来的 绿色贸易壁垒严重的影响了我国农产品的出口发展, 但是 外部原因是无法控制的, 积极发现并解决内部原因才是最 重要的。因此本节主要从内部原因来分析我国农产品遭遇 绿色贸易壁垒的原因。

\section{1. 农产品质量较低}

长期以来, 我国政府对农业发展十分重视, 经过几十 年的发展, 我国成为农产品生产大国, 也是农产品出口大 国, 但是在发展的过程中, 我们一昧的追求农产品的产量,
却忽视了农产品的质量, 导致现在我国农产品的质量水平 仍然很低, 很多产品都不能达到发达国家的标准。

我国农产品质量低主要有三方面: 首先, 农业环保意 识淡薄。焚烧秥秆、过量使用化肥农药在我国很常见, 这 导致我国农田遭到很严重的破坏, 农产品的质量很难提高; 其次, 农业的经营方式落后。目前, 我国农产品的生产方 式以小规模分散经营为主, 专业化程度非常低, 很难像发 达国家那样采用统一的标准严格控制产品质量; 最后, 农 产品生产技术落后。我国农业发展起步晚, 对农产品质量 要求不高, 因此没有及时的引进先进的农业技术, 另外我 国农业专业化程度比较低, 没有条件引进先进的环保技术, 造成现在农产品技术落后, 农产品品质较低。

\section{2. 农产品的质量标准较低、检测体系比较落后}

我国农产品建立了质量标准体系, 包括国家标准、行 业标准、地方标准, 但是和发达国家相比, 我国的质量标 准比较低, 很多产品的标准都不能满足发达国家的要求。 此外, 发达国家拥有先进的研发能力, 当他们取得新的技 术成果, 便会对其本国的标准进行提高, 使得我们更多的 产品达不到他们的标准。

农产品要达到出口目的地的标准, 必须经过相关部门 的检测, 但是目前我国的检测设备比较落后, 检测标准陈 旧, 检测数量少, 检测时间长, 达不到对农产品的监督作 用, 另外相对于发达国家一流的检测设备, 很多微量元素 在我国的设备上都很难被检测到, 这导致我们很多元素不 能达到发达国家的标准。

\section{3. 农产品的贸易信息不通畅}

我国农产品频繁遭遇绿色贸易壁垒的一个重要原因 就是贸易信息不通畅。发达国家经济技术水平发展很快, 为了保护他们本国产业, 减少国外产品的进口, 他们会及 时的用先进的科学技术提高进口标准。由于国内信息机制 不完善, 出口商可能很久以后才得到进口国发布的改变标 准的信息, 造成很多按原标准生产的货物积压在进口国的 口岸, 遭到进口国的绿色贸易壁垒。在我国, 贸易信息不 通畅已经造成很多农产品的贸易摩擦及不必要的损失。

\section{4. 我国农产品出口应对绿色贸易壁垒的对策建 议}

\section{1. 全面提高农产品质量}

我国农产品之所以频繁遭遇发达国家的绿色贸易壁 垒, 最重要的原因就是农产品质量达不到发达国家的要求。 因此, 走出重重绿色贸易壁垒, 最有效的方式就是全面提 高农产品的质量。

农产品质量受多种因素的影响，因此必须从多方面改 进以提高农产品质量: 第一, 提高农业环保意识。在我国, 农业环保意识很薄弱, 农药、化肥、禽粪的过量使用很常 见, 这不仅污染了土地、影响了产品质量, 还对河流、空 气等造成了严重的影响。因此政府应该加大监督力度, 积 
极指导农业对农药化肥的使用, 并且加强对绿色环保意识 的宣传, 使得企业、消费者增强绿色环保意识; 第二, 改 变农业经营方式。我国农业生产方式主要以小规模分散经 营为主, 专业化程度很低, 很难采用统一的标准, 导致产 品质量参差不齐, 不具有竞争力。因此, 我国应积极借鉴 发达国家的经营方式, 采用农场、兼业农户化和合作社等 方式, 提高农业规模, 采用统一高标准控制产品质量; 第 三，提高农产品生产技术。以前我国农业没有意识到技术 的重要性, 追求产量的同时没有兼顾到质量, 导致产品品 质达不到发达国家的要求, 从而遭受频繁的绿色贸易壁垒。 我国应吸取经验教训, 积极引进先进的技术, 提高农产品 的质量。

\section{2. 完善我国农产品质量标准体系和检测体系}

目前, 虽然我国农产品拥有一系列的质量标准体系, 但是这些体系还都处于完善阶段, 很多标准都低于国际标 准, 而发达国家的标准一般依据国际标准制定，甚至高于 国际标准, 因此我国应参考国际统一标准, 尽快建立一套 与国际标准相符合的质量标准体系。

检测体系对农产品质量的监督绝对不容忽视, 它是农 产品质量监督的最后一个环节。我国应积极完善检测体系, 适应市场发展需求, 进行检测设备的更新换代, 提高检测 标准, 增加检测项目和种类的同时提高检测效率, 与发达 国家的检测标准接轨。

\section{3. 建立行业信息机制、预警机制}

近年来, 由于贸易信息不通畅而导致我国农产品遭遇 绿色贸易壁垒的情况很多, 给我国造成了严重的经济损失。 因此, 我国应高度重视信息机制、预警机制的建设, 成立 专门的机构, 组织专业的人才, 通过驻外大使馆、领事馆 加强对国外信息的搜集与研究, 尤其是我国重点出口的日 本、欧盟、美国等市场, 并且根据这些搜集的信息形成预 警平台, 及时通报国际市场上我国农产品的情况, 让农产 品出口企业可以及时应对市场变化, 最大限度的降低农产 品的出口风险, 减少贸易摩擦及不必要的损失。

\section{5. 结语}

随着经济全球化和国际贸易的发展, 绿色贸易壁垒已 成为国际贸易保护的主要特征。发达国家打着保护环境的 旗帜, 对发展中国家进行贸易限制。面对绿色贸易壁垒, 任何国家和企业都很难置身事外, 所以我国作为世界第二 大经济体, 必须动员各方面力量, 采取积极有效的措施应 对绿色贸易壁垒, 开创我国农产品贸易新局面。

\section{致谢}

完成这篇论文, 得到了各方面的支持和关爱。首先, 要感谢我的导师李靖, 本文是在李靖老师精心指导和大力 支持下完成的。李靖老师严谨细致、一丝不苟的作风一直
是我工作、学习中的榜样; 他循循善诱的教导和不拘一格 的思路给予我无尽的启迪。这篇论文的每个细节和数据, 都离不开李老师细心的指导。感谢我的室友们, 从遥远的 家来到这个陌生的城市里, 是你们和我共同维系着彼此之 间兄弟般的感情, 维系着寝室那份家的融洽。感谢我的父 母, 谢谢你们一路以来的支持, 你们永远健康快乐是我最 大的心愿。最后, 我再次诚心诚意为所有关心和帮助过我 的人们表示衷心的感谢和深深的祝福!

\section{参考文献}

１１）海闻著. 国际贸易 [M]. 香港: 智慧出版社有限公司, 2013, 77。

[2] 金缀桥. 浅析新贸易保护主义的理论基础 [M]. 北京:中国经 济出版社, 2012, 13-15。

[3] 徐龙伟, 张正德. 如何应对国外的新贸易保护主义 [M]. 北京： 光明出版社, 2012, 41-43。

[4] 梁艳. 绿色贸易壁垒现状及对进出口国的影响分析 $[\mathrm{J}]$. 内 江师范学院学报, 2016, (01)。

[5] 邱翔. 我国面临的绿色贸易壁垒问题及应对策略分析 [J]. 现代营销 (学苑版), 2015, (03)。

６］汪欣, 高海燕. 绿色贸易壁对我国出口贸易的影响及对策 [J]. 全国商业经典, 2015, (07)。

［7］马明欢. 中国与东盟国家农业贸易技术性贸易壁垒法律制 度研究 $[J]$. 云南大学, 2015, (11)。

８］顾蓓蓓, 张磊. 发达国家技术贸易壁垒对我国农产品出口的 影响及对策 $[J]$. 安徽农业科学, 2014, (04)。

[9] 薛妮. 茶叶贸易中绿色壁垒及法律对策研究 [J]. 农业考 古, 2014, (06)。

[10］王剑文. 环境贸易壁垒对出口企业竞争力的影响及对策 $[\mathrm{J}]$. 江苏科技信息, 2014, (06)。

[11] 罗杰. 国际贸易一般原则与 CISG 漏洞补缺 $[\mathrm{J}]$. 理论月 刊, 2013, (11)。

[12] 陈万灵. 经济危机下贸易保护主义新趋势及其对策 $[\mathrm{J}]$. 对 外经贸实务, 2013, (06)。

[13] 李宇. 浅论如何构建中国的国际贸易政策保护性 [J]. 中国 科技博览, 2012, (09)。

[14] 徐晓莉. “中国制造” 如何突破贸易保护主义的重围 $[J]$. 对外经贸实务, 2012, (11)。

[15] 刘媛. 贸易保护主义的弊端及应对策略 [D]. 北京: 北京大学 出版社, 2013:179-193。 